ACADEMIA ROMÂNĂ

Revue Roumaine de Chimie

http://web.icf.ro/rrch/
Rev. Roum. Chim.

2020, 65(7-8), 635-646

DOI: $10.33224 /$ rrch.2020.65.7-8.01

Review

\title{
THE ROLE OF THE SUBSTITUENTS IN THE CHEMISTRY OF ORGANOANTIMONY(I) COMPOUNDS
}

\author{
Hans Joachim BREUNIG* \\ Institut für Anorganische und Physikalische Chemie, Universität Bremen, D-28334 Bremen, Germany
}

Depending on the nature of the substituents organoantimony(I) compounds exist as polymeric chains, as cyclic compounds, dimeric or monomeric species. The influence of the substituent is discussed in this article.

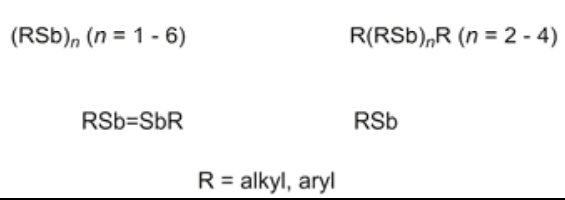

\section{INTRODUCTION}

Constitutive for organometallic compounds is the presence of an organic group bonded to the metal and this is of course also true for organoantimony (I) compounds which are considered in this review article. Organoantimony(I) compounds are monomers of the type $\mathrm{RSb}$, dimers $\mathrm{RSb}=\mathrm{SbR}$, cyclooligomers $(\mathrm{RSb})_{n}$ or polymers $(\mathrm{RSb})_{x}$ where $\mathrm{R}$ is an organic group which is bonded through a $\mathrm{Sb}-\mathrm{C}$ bond to an antimony atom. RSb units exist also in catenastibanes of the type $\mathrm{R}_{2} \mathrm{Sb}(\mathrm{SbR})_{n} \mathrm{SbR}_{2}$ or in complexes with organoantimony(I) ligands.

It is believed that this class of compounds may illustrate in an exemplary way the role of organic groups bonded to a metal because there is a large variety of types of compounds and the chemical behavior is multifold. The chemistry of organoantimony(I) compounds is particularly sensitive to the nature of the organic groups, which are often named organic substituents or organic ligands. The name substituent reflects the fact that the antimony carbon bonds are often described as covalent with a polar character and positive partial charges on the metal and negative partial charges on the carbon atom. The name ligand reminds more of the polar character of the antimony carbon bonds. In fact in an extreme view the carbon metal bond can be considered as the coordination of a carbanionic ligand through the lone pair of electrons at the carbon atom into an empty orbital of the metal.

The role of the organic groups is multifold. One basic role is to control the chemical functions of a molecule. Equally important are the sterical and electronic and coordinating effects of the group $\mathrm{R}$ that lead to formation of various molecules that are composed of RSb moieties. The most important coordinating effect is the denticity of the organic ligand. In organoantimony(I) chemistry mono-, biand tridentate ligands have been used.

It is the art and the hard labor of the preparative chemist to choose appropriate organic groups and

\footnotetext{
${ }^{*}$ Corresponding author: hbreunig@uni-bremen.de
} 
to design and to synthesize novel protecting groups for the stabilization of the desired molecules.

When selecting the organic group for organoantimony(I) compounds several aspects have to be considered. One important factor is the stability of the antimony carbon bond with respect to the elimination of the organic group. A known process of elimination which also plays a role in alkylantimony chemistry is the $\beta$-elimination process which leads to the formation of an alkene and transfer of a hydrogen atom from the $\beta$-position of the carbon chain to the metal (Scheme 1).

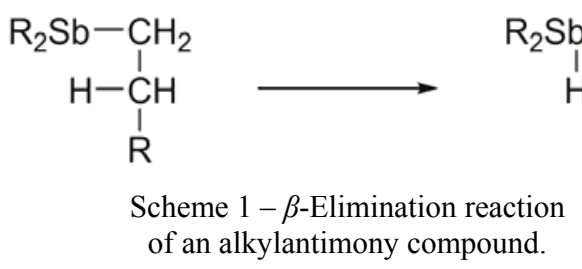

This process can play a role for the ethyl, $n$-propyl-, isopropyl-, tertiary butyl groups which possess $\beta$-hydrogen atoms but is not possible for substituents without a $\beta$-hydrogen atom like the methyl- or neopentyl group. $\beta$-Elimination was observed for ethyl- and n-popylantimony(I) compounds by mass spectrometry. ${ }^{1}$

There is also a stabilizing silyl effect and therefore it is not surprising that the trimethylsilylmethyl- and the bis(trimethylsilyl)methyl groups, $\mathrm{Me}_{3} \mathrm{SiCH}_{2}$, $\left(\mathrm{Me}_{3} \mathrm{Si}\right)_{2} \mathrm{CH}-$, have been found particularly useful for the protection of organoantimony(I) compounds. The $\left(\mathrm{Me}_{3} \mathrm{Si}\right)_{2} \mathrm{CH}-$ group is sterically protecting the antimony centers in a specific way in the periphery of the molecule without too much sterical repulsion inside the molecule. Another advantage is the usefulness of this group for the structural analysis of the molecules by ${ }^{1} \mathrm{H}-\mathrm{NMR}$ spectroscopy. Important is also the influence of the organic groups on the solubility of the organoantimony(I) compounds in organic solvents, where other structures may be adopted than in the solid. For purification processes in solution and for structural studies in solution a sufficient solubility is required. The study of methyland phenylantimony(I) compounds by ${ }^{1} \mathrm{H}-\mathrm{NMR}$ methods in solution is for instance affected by low solubilities. Generally substituted phenyl groups are suitable because of the relative stability of the aryl antimony bond and protecting steric effects which are pronounced when substituents are situated in the ortho positions of the phenyl ring. One of several examples is the mesityl group. An important factor is also the influence of the organic group on the volatility. A volatile compound that can be purified by sublimation and easily be studied by mass spectrometry is $(t-\mathrm{BuSb})_{4}$.

Very useful for the stabilization of organoantimony(I) compounds are ligands with pendant arms like 2-( $\left.\mathrm{Me}_{2} \mathrm{NCH}_{2}\right) \mathrm{C}_{6} \mathrm{H}_{4}-, \quad 2,6-\left(\mathrm{Me}_{2} \mathrm{NCH}_{2}\right)_{2} \mathrm{C}_{6} \mathrm{H}_{3}-$ group and similar groups. These groups can coordinate on the antimony centers as bidentate $\mathrm{N}, \mathrm{C}$ ligands or as tridentate $N, C, N$-ligands. They increase substantially the sterical and electronic protection of organoantimony(I) centers and hence the stability with respect to thermal decomposition and air stability. Bidentate and tridentate ligands are more firmly bonded to the metal due to the chelate effect and the sterical protection is increased with larger numbers of coordinating atoms.

The chemistry of RSb species has been considered repeatedly in chapters of review articles. ${ }^{2-}$ ${ }^{8}$ None of these articles was focused exclusively on organoantimony(I) chemistry and the role of the organic substituents. Protecting groups for the stabilization of inter-element linkages were reviewed by Yoshifuji. ${ }^{9}$ Principles of pincer ligands were recently summarized by van Koten. ${ }^{10}$ Applications of organoantimony (I) compounds comprise the use as reagents in organo antimony chemistry and in coordination chemistry and as sources for "naked" $\mathrm{Sb}_{n}$ species. Organoantimony(II) and -(III) compounds have been applied for the preparation of semiconducting $\mathrm{SbM}\left(\mathrm{M}=\mathrm{Al}\right.$, In, Ga) materials. ${ }^{11}$ Organoantimony $(\mathrm{V})$ compounds were studied as materials for the capture and the sensing of small ions and molecules such as $\mathrm{F}^{-}, \mathrm{CN}^{-}, \mathrm{O}_{2}, \mathrm{CO}_{2}{ }^{12}$

In this article a timely overview rather than a comprehensive report on the field of RSb-compounds is given and the influence of the $\mathrm{R}$ groups on the chemical behavior of organoantimony(I) compounds is discussed.

\section{HISTORICAL ASPECTS}

The first known organometallic compound of antimony was triethylantimony. This compound was reported by Löwig in 1850 with the name Stibäthyl. ${ }^{13}$ In this article also the fragment ethylantimony was mentioned in a speculative way as a radical with the name Aethylstibyl and the formula $A e S b$. Triethylantimony was believed to consist of Aethylstibyl and two less firmly bonded ethyl groups and the formula (AeSb), $A e_{2}$ was used for triethylantimony. This consideration does not have much chemical background but it may be of historic interest that the very first paper of organoantimony chemistry mentions an organo- 
antimony $(\mathrm{I})$ species $\mathrm{RSb}(\mathrm{R}=\mathrm{Et})$, which is named today ethylstibinidene. Ethylstibinidene is still unknown, but cyclo-oligomers $(\mathrm{RSb})_{n}(\mathrm{R}=\mathrm{Et}$, $n=3-5$ ) were described.

More chemical background than Aethylstibyl have the Stibino compounds that were mentioned by Ehrlich and Karrer in 1913 in the context of the search for antimony analogues of the famous medicament Salvarsan. ${ }^{14}$ These compounds were described with the formula $\mathrm{RSb}=\mathrm{SbR}(\mathrm{R}=$ aryl group). In 1920 Schmidt described a Stibiobenzol (in English stibiobenzene) with the formula $\mathrm{PhSb}=\mathrm{SbPh} .{ }^{15}$ The structure of Schmidt's stibiobenzene is not known, but it is very unlikely that there is a double bond between the antimony atoms in that compound. Very likely it is polymeric like several ill characterized organoantimony(I)compounds.

The first cyclic organoantimony(I) was $(\mathrm{RSb})_{4}$ $(\mathrm{R}=t-\mathrm{Bu})$ reported by Issleib in 1965 and in the coming years rings, dimers and monomers (RSb) $(n=1-6)$ and other RSb species were synthesized with the help of more and more sophisticated $\mathrm{R}$ groups. The dynamic development in the field of $\mathrm{RSb}$ oligomers and monomers contrasts with stagnation of the research in the field of polymers $(\mathrm{RSb})_{x}$ where many synthetic and analytical problems are not solved.

\section{METHYLANTIMONY(I) COMPOUNDS}

Methylantimony(I) compounds are particularity challenging because, in contrast to the analogous methylarsenic system, which comprises the famous ladder polymer (MeAs) $)_{x}$ and the well-defined cycle $(\mathrm{MeAs})_{5}$ only very little is known in the field of MeSb compounds. ${ }^{16}$ Despite several attempts by different research groups only ill-defined polymers were described and signals of oligomeric species were detected by mass spectrometry. ${ }^{17}$

An early attempt to synthesize methylantimony was the thermal decomposition of $\mathrm{MeSbH}_{2}$ by Burg and Grant. ${ }^{18}$ However the antimony content of the product was higher than required for the formula $(\mathrm{MeSb})_{x}$.

Rheingold obtained a purple black polymer of the composition $(\mathrm{MeSb})_{\mathrm{x}}$ from dibenzylmercury and $\mathrm{MeSbH}_{2}$ and from $\mathrm{MeSbH}_{2}$ and $\mathrm{Me}_{2} \mathrm{SiCl}_{2}$ at $-78{ }^{\circ} \mathrm{C} .{ }^{16}$ The structure of the polymer was not determined. In the 1980's and 1990's we studied the methylantimony system and found that methylantimonydibromide can be reduced by magnesium filings in tetrahydrofuran to form a black solid material where the elemental composition fits to $\mathrm{Br}(\mathrm{SbMe})_{13} \mathrm{Br}$. This material reacts with excess $\mathrm{Me}_{2} \mathrm{SbSbMe}_{2}$ and magnesium in tetrahydrofuran to give a solution containing the distibane together with the tristibane $\mathrm{Me}_{2} \mathrm{Sb}(\mathrm{SbMe}) \mathrm{SbMe}_{2}$, which is also formed from $\mathrm{Me}_{2} \mathrm{SbBr}, \mathrm{MeSbBr}_{2}$ and magnesium. Removal of the distibane and the solvent at reduced pressure leads to a black shiny solid with $\mathrm{C}$ and $\mathrm{H}$ elemental analysis corresponding to the formula $\mathrm{Me}_{2} \mathrm{Sb}(\mathrm{SbMe})_{11} \mathrm{SbMe}_{2}$, which is not soluble in water or in organic solvents. The structure of this material which can be prepared as solid films was not determined. Mass spectra showed signals of $\mathrm{Me}_{4} \mathrm{Sb}_{2}$ and the oligomers $(\mathrm{MeSb})_{n}(n=3-5) .{ }^{1,17,19}$

In an attempt to synthesize complexes with methylantimony rings as ligands we reacted $\left[\mathrm{MeSbBr}_{2} \mathrm{Cr}(\mathrm{CO})_{5}\right]$ with magnesium and obtained a mixture of ring complexes which was analyzed by mass spectrometry and the peaks corresponding to ring complexes $\left.(\mathrm{MeSb})_{5}\left[\mathrm{Cr}(\mathrm{CO})_{5}\right)_{\mathrm{n}}\right](\mathrm{n}=1-3)$, $\left[(\mathrm{MeSb})_{4}\left\{\mathrm{Cr}(\mathrm{CO})_{5}\right\}_{\mathrm{n}}\right] \quad(\mathrm{n}=1,3)$, and $(\mathrm{MeSb})_{3}\left[\mathrm{Cr}(\mathrm{CO})_{5}\right]$ were detected. The ${ }^{1} \mathrm{H}-\mathrm{NMR}$ signals were found to be too complex for a full analysis. ${ }^{17}$

The main role of the methyl group in organoantimony(I) chemistry is to favor formation of polymers $(\mathrm{MeSb})_{x}$ which, despite the analytical difficulties, deserve attention as analogues of the unique methyl arsenic ladder chain and as promising materials. The methyl group forms strong bonds to antimony with a minimum of steric hindrance and therefore it is the perfect group for stabilizing antimony chains with strong inter chain contacts in the solid state. Unfortunately a full structural characterization of $(\mathrm{MeSb})_{x}$ was not achieved, due to the fact that analytical tools for the analysis of organometallic polymers are scarce.

\section{ETHYLANTIMONY(I) COMPOUNDS}

A major step forward in the chemistry of RSb species was achieved with the ethyl substituent. ${ }^{1,20}$ The ethyl group is more bulky than the methyl group and due to the longer alkyl chain the solubility in hydrocarbons is increased. These effects contribute to the existence of cyclic species, i.e. cyclo-(EtSb) $)_{4}$ and cyclo-(EtSb $)_{5}$ in solution in $\mathrm{C}_{6} \mathrm{D}_{6}$. The rings were characterized by ${ }^{1} \mathrm{H}-\mathrm{NMR}$ spectroscopy with variation of concentration and ring-ring equilibrium between the ethyl antimony four and five rings was detected. In $\mathrm{C}_{6} \mathrm{D}_{6}$ at room temperature the five ring $(88 \%)$ is more abundant than the four ring $(12 \%)$. The ${ }^{1} \mathrm{H}-\mathrm{NMR}$ spectra fit to the presence of the cis-trans isomers of cyclo- 
$(\mathrm{EtSb})_{5}$ and all-trans of cyclo-(EtSb) $)_{4}$ with time averaged planar structures were the signals of the five ring belong to two $\mathrm{ABX}_{3}$ spin systems and one $\mathrm{A}_{2} \mathrm{X}_{3}$ spin system in the 2:2:1 ratio of intensities, and the signals of the four ring to one $\mathrm{A}_{2} \mathrm{X}_{3}$ spin system. The increase of the intensities of the signals from the four ring on dilution confirm these assignments. Removal of the solvents led to the formation of the ethylantimony polymer, $(\mathrm{EtSb})_{x}$, a black solid which can be prepared as black shiny films. The process is reversible and from the solid the yellow solution can be obtained again. The equilibria are shown in Scheme 2.

Unfortunately the structure of the black solid was not determined. The ethyl antimony system was also studied by mass spectrometry. From the black solid and from concentrated solutions of the rings the signals of the oligomer ions $\mathrm{Et}_{3} \mathrm{Sb}_{3}{ }_{3}$, $\mathrm{Et}_{4} \mathrm{Sb}_{4}{ }^{+}, \mathrm{Et}_{5} \mathrm{Sb}_{5}{ }^{+}$were detected. Reactions of $(\mathrm{EtSb})_{x}$ with dichalcogenides REER gave $\mathrm{EtSb}(\mathrm{ER})_{2}(\mathrm{E}=\mathrm{Se}, \mathrm{Te} ; \mathrm{R}=\mathrm{Me}, \mathrm{Ph}) .(\mathrm{EtSb})_{x}$ reacts with air and bromine to give, (EtSbO) $)_{x}$ and $\mathrm{EtSbBr}_{2}$, respectively. (EtSbO) $)_{x}$ was not structurally characterized. The electrical conductivity of the polymers $(\mathrm{EtSb})_{x}$ was measured on tablets formed from the powders under pressure and the value $\sigma=210^{-4} \mathrm{~S} \mathrm{~cm}^{-1}$ was determined. This value corresponds to a very low conductivity. (EtSb) $x$ was also characterized by ${ }^{121} \mathrm{Sb}$ Mössbauer spectroscopy. ${ }^{21}$

The role of the ethyl group in RSb compound is to stabilize rings in solution but not in the solid state and therefore in the ethylantimony system both ring-ring equilibria in solution and ring-chain equilibria between the solution and the solid phase are established. The isolation and crystallization of specific rings was not achieved. All attempts led to the formation of the polymer.

\section{n-PROPYL-, ISOPROPYL, $n$-BUTYL, ISOBUTYL- ANTIMONY CYCLO- OLIGOMERS AND POLYMERS}

The behavior of the $n$-propyl, isopropyl, and $n$-butyl antimony systems is similar to that of the ethyl antimony system, i.e. four and five membered rings are present in solution and the transition to the solid state leads to the formation of ill defined $(\mathrm{RSb})_{x}$ polymers. ${ }^{1,19}$ In $_{6} \mathrm{C}_{6}$ solution the five rings $(\mathrm{RSb})_{5}[\mathrm{R}=n-\operatorname{Pr}(95 \%), i-\operatorname{Pr}(72 \%), n-\mathrm{Bu}(93 \%)]$ are more abundant than the four rings $(\mathrm{RSb})_{4}[\mathrm{R}=$ $n-\operatorname{Pr}(5 \%), i-\operatorname{Pr}(28 \%), n-\mathrm{Bu}(7 \%)]$. The electrical conductivity of the polymers $(\mathrm{RSb})_{x}$ was measured on tablets formed from the powders under pressure and the values $\sigma=210^{-4} \mathrm{~S} \cdot \mathrm{cm}^{-1}(\mathrm{R}=n-\mathrm{Pr})$ and $10^{-5}$ $\mathrm{S} \cdot \mathrm{cm}^{-1}(\mathrm{R}=n-\mathrm{Bu})$ were found. Attempts to further characterize the polymers met with little success. Also electrosynthetic methods gave only powders of the polymers. ${ }^{22}$

The $n$-propylantimony rings react in solution in $\mathrm{C}_{6} \mathrm{D}_{6}$ with the ethylantimony rings with formation of mixed $n$-propylethylantimony four and five membered rings in equilibria. ${ }^{20}$

The role of the $n$-alkyl substituents $\mathrm{R}=\mathrm{Et}, n$-Pr, $n$-Bu in RSb systems is to favor five rings over four rings in solution and to favor the formation of polymers on transitions into the solid state. There is little chance to isolate specific rings. It is remarkable that the larger sterical demand of the isopropyl group, $i$-Pr causes a significant increase of the fraction of the four ring on the cost of the five ring.

Like previously discussed systems also the isobutylantimony(I) system contains four and five rings, cyclo-( $\mathrm{RSb})_{n}(n=4,5 ; \mathrm{R}=i$-Bu) which are formed from $\mathrm{RSbBr}_{2}$ and magnesium. ${ }^{23}$ Solutions of the rings consist of $96 \mathrm{~mol} \%$ of the pentamer and $4 \mathrm{~mol} \%$ of the tetramer. A special aspect is however that the rings or probably only the five membered ring can be obtained as yellow crystals together with a black solid, probably the polymer. The role of the isobutyl group is to stabilize alkyl antimony four and five membered rings which exist both in solution and probably also in the solid state.

\section{NEOPENTYL- AND \\ TRIMETHYLSILYLMETHYLANTIMONY(I) COMPOUNDS}

The organoantimony(I) compounds with neopentyl and the trimethylsilylmethyl substituents are obtained by reaction of the corresponding alkylantimony dibromides with magnesium in tetrahydrofuran. ${ }^{24-26}$ In solution there are four and five rings $(\mathrm{RSb})_{n}\left(\mathrm{R}=\mathrm{Me}_{3} \mathrm{CCH}_{2}, \mathrm{Me}_{3} \mathrm{SiCH}_{2}\right)$. The five rings are more abundant. In the crystalline state there are pentamers. The crystals of $\left(\mathrm{Me}_{3} \mathrm{CCH}_{2} \mathrm{Sb}\right)_{5}$ and $\left(\mathrm{Me}_{3} \mathrm{SiCH}_{2} \mathrm{Sb}\right)_{5}$ were analyzed by single-crystal $\mathrm{X}$-ray diffractommetry. The structure analysis of the latter suffered from disorder but the structure of $\left(\mathrm{Me}_{3} \mathrm{CCH}_{2} \mathrm{Sb}\right)_{5}$ was determined. Crystals consist of $\mathrm{Sb}_{5}$ rings in an envelope conformation with the substituents in a maximum of trans positions. The five rings are weakly associated to chains through intermolecular 
contacts between antimony atoms. Both rings, $\left(\mathrm{Me}_{3} \mathrm{CCH}_{2} \mathrm{Sb}\right)_{5}$ and $\left(\mathrm{Me}_{3} \mathrm{SiCH}_{2} \mathrm{Sb}\right)_{5}$, have characteristic ${ }^{1} \mathrm{H}-\mathrm{NMR}$ spectra (three singlet signals in a 2:2:1 intensity ratio for the methyl groups as well as a singlet and eight signals of two $\mathrm{AB}$ spin systems for the methyl groups) which indicate the presence of an effective plane of symmetry with two pairs of chiral antimony atoms. ${ }^{25}$ Reduction of $\mathrm{RSbCl}_{2}$ with magnesium gives also a polymer, $(\mathrm{RSb})_{x}\left(\mathrm{R}=\mathrm{Me}_{3} \mathrm{SiCH}_{2}\right){ }^{26}$ With the distibanes $\mathrm{Me}_{2} \mathrm{SbSbMe}_{2}$ or $\mathrm{Ph}_{2} \mathrm{SbSbPh}_{2}$ the rings form the catena-tri- and tetrastibanes $\mathrm{R}_{2}^{\prime} \mathrm{Sb}(\mathrm{SbR})_{n} \mathrm{SbR}_{2}^{\prime}\left(\mathrm{R}^{\prime}=\mathrm{Me}, \mathrm{Ph} ; \mathrm{R}=\mathrm{Me}_{3} \mathrm{CCH}_{2}\right.$, $\left.\mathrm{Me}_{3} \mathrm{SiCH}_{2}, n=1,2\right)$ in equilibria reactions. The catena-tetrastibanes $\quad \mathrm{R}_{2} \mathrm{Sb}\left(\mathrm{SbCH}_{2} \mathrm{SiMe}_{3}\right)_{2} \mathrm{SbR}_{2}$ ( $\mathrm{R}=\mathrm{Me}, \mathrm{Ph}$ were trapped as complexes of the type cyclo- $\mathrm{Cr}(\mathrm{CO})_{4} \mathrm{R}_{2} \mathrm{Sb}\left(\mathrm{SbCH}_{2} \mathrm{SiMe}_{3}\right)_{2} \mathrm{SbR}_{2}{ }^{27}$ The formation of the complexes is shown in Scheme 3.

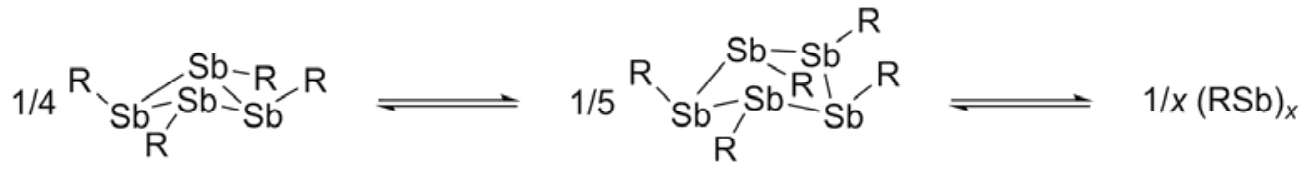

Scheme 2 - Ring-ring and ring chain equilibria in the ethyl antimony system $(R=E t)$.

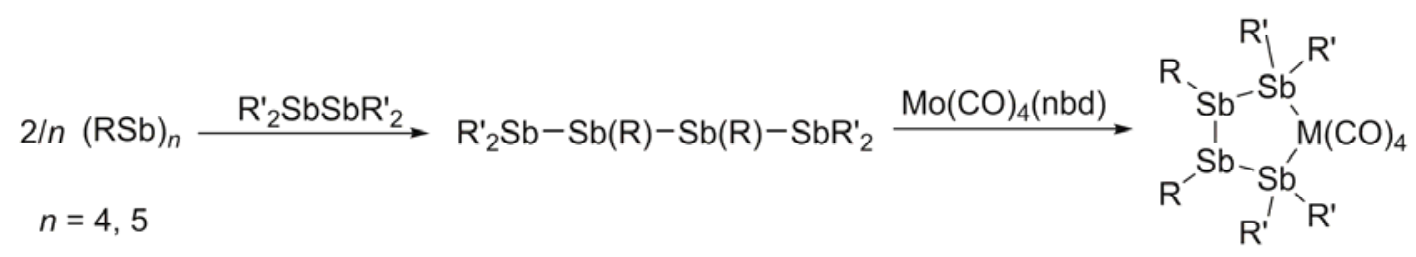

Scheme 3 - Ring chain reactions and formation of tetrastibane complexes

$\left(\mathrm{R}=\mathrm{Me}_{3} \mathrm{SiCH}_{2}, \mathrm{R}^{\prime}=\mathrm{Me}, \mathrm{Ph} ; \mathrm{M}=\mathrm{Cr} ; \mathrm{nbd}=\right.$ norbornadiene $)$.

$\left(\mathrm{Me}_{3} \mathrm{SiCH}_{2} \mathrm{Sb}\right)_{5}$ serves as ligand in $\left[\left(\mathrm{Me}_{3} \mathrm{SiCH}_{2} \mathrm{Sb}\right)_{5} \mathrm{~W}(\mathrm{CO})_{5}\right] .{ }^{28}\left(\mathrm{Me}_{3} \mathrm{CCH}_{2} \mathrm{Sb}\right)_{n}(n=4$, 5) reacts with $\left[\mathrm{MeC}_{5} \mathrm{H}_{4} \mathrm{Cr}(\mathrm{CO})_{3}\right]_{2}$ to form $\left[\left(\mathrm{Me}_{3} \mathrm{CCH}_{2} \mathrm{Sb}\right)_{4}\left[\mathrm{MeC}_{5} \mathrm{H}_{4} \mathrm{Cr}(\mathrm{CO})_{3}\right]_{2} .{ }^{29}\right.$ Reactions of $\left(\mathrm{Me}_{3} \mathrm{SiCH}_{2} \mathrm{Sb}\right)_{5}$ with the ditelluride $(p \text {-TolTe })_{2}$ gives $\mathrm{Me}_{3} \mathrm{SiCH}_{2} \mathrm{Sb}[\mathrm{Te}(p-\mathrm{Tol})]_{2}{ }^{26}$

The neopentyl and trimethylsilyl groups proved to be particularly useful for the stabilization of five membered antimony rings. The shape of the groups allowed protection in the periphery of the five rings without hindering the close vicinity of two groups in cis positions, which is unavoidable in five membered antimony rings. The five rings can be crystallized from the equilibrium mixture with the four rings without polymerization. Neopentyland trimethylsilyl antimony units are central elements in catena tri- and tetrastibanes, the latter being the only organoantimony chains that were trapped in complexes and characterized by singlecrystal X-ray diffraction. Neopentyl- and trimethylsilylmethyl antimony rings are useful reagents for the synthesis of main group element and transition metal compounds.

\section{THE}

\section{BIS(TRIMETHYLSILYL)METHYLANTIMONY RING SYSTEM}

A substituent that has been widely used in organometallic chemistry as spacious protecting substituent is the $\left(\mathrm{Me}_{3} \mathrm{Si}\right)_{2} \mathrm{CH}$ group. The absence of a hydrogen atom in $\beta$ position, a stabilizing silyl effect and the shape of the substituent with protection in the periphery of the molecule and little repulsion in the interior of a ring molecule contributes to the high protecting qualities of this substituent for organoantimony(I) systems, which led to the isolation of crystalline three and four rings and polycyclic ring systems. The rings $c i s-$ trans $(\mathrm{RSb})_{3}$ and all-trans $(\mathrm{RSb})_{4}\left[\mathrm{R}=\left(\mathrm{Me}_{3} \mathrm{Si}\right)_{2} \mathrm{CH}\right]$ were first obtained by reaction of $\mathrm{RSbCl}_{2}$ with $\mathrm{Mg}$ in tetrahydrofuran. ${ }^{30}$ The three ring is formed selectively from $\mathrm{Li}_{3} \mathrm{Sb}$ and $\mathrm{RSbCl}_{2}$ at $-40{ }^{\circ} \mathrm{C}$ in tetrahydrofuran. Both rings are thermally stable in the solid state and in solution in absence of oxygen without taking part in ring-ring equilibria. The crystal structure determination of the tetramer revealed the structure of a folded four ring, alltrans $\left[\left(\mathrm{Me}_{3} \mathrm{Si}\right)_{2} \mathrm{CHSb}\right]_{4}$ with the substituents in the trans position. ${ }^{19}$ The structure of the three membered ring was also determined by X-ray crystallography and ${ }^{1} \mathrm{H}-\mathrm{NMR}$ spectroscopy as cistrans cyclo- $\left[\left(\mathrm{Me}_{3} \mathrm{Si}\right)_{2} \mathrm{CHSb}\right]_{3}{ }^{31}$ The three membered ring can also be generated photochemically in UV light through ring contraction from the four ring. Not only the three and four ring but also the polycycles $\mathrm{Sb}_{8} \mathrm{R}_{4}$ and $\mathrm{Sb}_{7} \mathrm{R}_{5}$ are formed by reduction of $\mathrm{RSbCl}_{2}[\mathrm{R}=$ $\left.\left(\mathrm{Me}_{3} \mathrm{Si}\right)_{2} \mathrm{CH}\right]$. The structure of $\mathrm{Sb}_{8} \mathrm{R}_{4}$ as determined by single-crystal $\mathrm{X}$-ray crystallography is a tricyclic cage that can be derived from a $\mathrm{Sb}_{4}$ 
tetrahedron by insertion of RSb units in to the edges of the tetrahedron. ${ }^{32}$ Reduction of $\mathrm{RSbCl}_{2}[\mathrm{R}$ $\left.=\left(\mathrm{Me}_{3} \mathrm{Si}\right)_{2} \mathrm{CH}\right]$ with $\mathrm{Na}-\mathrm{K}$ alloy gives the four membered ring $(\mathrm{RSb})_{3} \mathrm{Sb}-\mathrm{SbR}-\mathrm{Sb}(\mathrm{R}) \mathrm{Cl}^{33}$

Useful starting materials for bis(trimethylsilyl)methylantimony(I) compounds are also the antimony hydrides $\mathrm{RSbH}_{2}[\mathrm{R}=$ $\left.\left(\mathrm{Me}_{3} \mathrm{Si}\right)_{2} \mathrm{CH}\right]$ and $\mathrm{R}(\mathrm{H}) \mathrm{Sb}-\mathrm{Sb}(\mathrm{H}) \mathrm{R}$. Reaction of $\mathrm{RSbH}_{2}$ with $\mathrm{SbCl}_{3}$ and pyridine gives the above mentioned polycycle $\mathrm{Sb}_{8} \mathrm{R}_{4}$. Dehydrogenation of meso- $\mathrm{R}(\mathrm{H}) \mathrm{Sb}-\mathrm{Sb}(\mathrm{H}) \mathrm{R}$ leads to the unique four ring cis-trans- $\mathrm{R}_{4} \mathrm{Sb}_{4}$, which in presence of light gives all-trans- $\mathrm{R}_{4} \mathrm{Sb}_{4}$ and $\mathrm{R}_{3} \mathrm{Sb}_{3}$. Decomposition of meso- $\mathrm{R}(\mathrm{H}) \mathrm{Sb}-\mathrm{Sb}(\mathrm{H}) \mathrm{R}$ in presence of $t-\mathrm{BuONa}$ produces the bicycle $(\mathrm{RSb})_{3} \mathrm{Sb}-\mathrm{Sb}(\mathrm{SbR})_{3}$. Elimination of hydrogen from $\mu$ $[\mathrm{R}(\mathrm{H}) \mathrm{Sb}-\mathrm{Sb}(\mathrm{H}) \mathrm{R}]\left[\mathrm{W}(\mathrm{CO})_{5}\right]_{2}$ or $\left[\mathrm{R}(\mathrm{H})_{2} \mathrm{SbW}(\mathrm{CO})_{5}\right]$ gives the distibene complex $\left[(\mathrm{RSb}=\mathrm{SbR}) \mathrm{W}(\mathrm{CO})_{5}\right]$ or the stibinidene complex $\left[\mathrm{RSb}\left\{\mathrm{W}(\mathrm{CO})_{5}\right\}_{2}\right]^{34}{ }^{34}$

The trimer $(\mathrm{RSb})_{3}\left[\mathrm{R}=\left(\mathrm{Me}_{3} \mathrm{Si}\right)_{2} \mathrm{CH}\right]$ is a versatile reagent for transition metal carbonyl complexes. The three ring reacts with $\left[\mathrm{Fe}_{2}(\mathrm{CO})_{9}\right]$ to give $\left[(\mathrm{RSb})_{3} \mathrm{Fe}(\mathrm{CO})_{4}\right]^{28}$ and with $\left[\mathrm{W}(\mathrm{CO})_{5}(\mathrm{thf})\right]$, $\left[\mathrm{MeC}_{5} \mathrm{H}_{4} \mathrm{Mn}(\mathrm{CO})_{2}(\right.$ thf $\left.)\right]$ or $\left[\mathrm{Co}_{2}(\mathrm{CO})_{8}\right]$ to form $\left[(\mathrm{RSb})_{3} \mathrm{~W}(\mathrm{CO})_{5}\right], \quad\left[\mathrm{RSb}\left\{\mathrm{MeC}_{5} \mathrm{H}_{4} \mathrm{Mn}(\mathrm{CO})_{2}\right\}_{2}\right]$ or $\left[(\mathrm{RSb})_{2}\left\{\mathrm{Co}(\mathrm{CO})_{3}\right\}_{2}\right]^{29}$

In the field of organoantimony ring compounds, the bis(trimethylsilyl)methyl group is the most widely used protecting group due to its stabilizing effect for three and four membered rings, for polycyclic systems, and for complexes with stibinidene, distibene and tristibane ligands. A feature of the group is the tolerance for cisarrangements as found in the three ring and in the cis-trans four ring. A remarkable chemical property is the tendency for photochemical ring contractions as found in the case of the four ring and the polycycle $\mathrm{R}_{4} \mathrm{Sb}_{8}$. The bis(trimethylsilyl)methylantimony(I) compounds are excellent ligands for transition metal complexes whose potential is far from being exhausted. Mainly complexes with transition metal carbonyls have been studied in the past. Promising future investigations might consider the ligand behavior of $(\mathrm{RSb})_{4}$ and reactions with other main group or transition metal complexes.

\section{TERT-BUTYLANTIMONY RINGS}

The tert-butylantimony(I) system consists of the four and five membered rings. Polymeric or polycyclic forms were not reported. cyclo- $(t-$ $\mathrm{BuSb})_{4}$ was first described by Issleib, Hamann and
Schmidt, who obtained the ring as byproduct of the reaction of $t-\mathrm{Bu}_{2} \mathrm{SbCl}$ with $\mathrm{LiAlH}_{4}$ as a red powder. ${ }^{29,}{ }^{35}$ Later the four ring was synthesized as yellow crystals by reaction of $t-\mathrm{Bu}_{2} \mathrm{SbCl}$ or $t$ $\mathrm{BuSbCl}_{2}$ with magnesium in tetrahydrofuran. ${ }^{36}$ The four ring is thermally stable in the solid state, in solution and in the gas phase, in an inert atmosphere. The ${ }^{1} \mathrm{H}-\mathrm{NMR}$ spectrum shows a singlet signal for the tert-butyl groups and the mass spectrum contains the molecular ion and fragment ions. Crystals can be obtained from solutions or by sublimation under reduced pressure. The molecular structure in crystals consists of a folded $\mathrm{Sb}$ four membered ring with all the tert-butyl groups in trans positions. In the solid state the four rings are well separated and no close intermolecular $\mathrm{Sb} \cdots \mathrm{Sb}$ contacts exist. This fact may contribute to the relative high volatility of the ring that can be sublimed easily at reduced pressure. ${ }^{37} \mathrm{~A}$ side product of the reaction of $t-\mathrm{BuSbCl}_{2}$ with magnesium is the five membered ring, cyclo- $(t-$ $\mathrm{BuSb})_{5}$ which however is not very well characterized. The mass spectrum shows characteristic signals and the ${ }^{1} \mathrm{H}-\mathrm{NMR}$ spectrum consists of signals for the tert-butyl groups in the 2:2:1 ration which is characteristic for the cis-trans configuration of the five membered ring. ${ }^{38}$

$(t-\mathrm{BuSb})_{4}$ was used repeatedly as reagent for the synthesis of transition metal complexes with antimony ligands. The ring can be used as intact ligand or as a source of antimony for naked $\mathrm{Sb}_{2}, \mathrm{Sb}_{3}$, or $\mathrm{Sb}_{5}$ ligands in transition metal complexes. The intact four ring reacts with $\left[\mathrm{W}(\mathrm{CO})_{5}(\mathrm{thf})\right]$ with formation $\quad\left[(t-\mathrm{BuSb})_{4} \mathrm{~W}(\mathrm{CO})_{5}\right]$ and $[(t-$ $\left.\mathrm{BuSb})_{4}\left\{\mathrm{~W}(\mathrm{CO})_{5}\right\}_{2}\right]$. The molecular structure of the latter was determined and it was shown that the $\mathrm{W}(\mathrm{CO})_{5}$ groups are coordinated by the $\mathrm{Sb}$ atoms in positions 1 and 3 of the four membered ring. ${ }^{39}$ Also the complexes $\left[(t-\mathrm{BuSb})_{4} \mathrm{Fe}(\mathrm{CO})_{4}\right]$ and $[(t-$ $\mathrm{BuSb})_{4} \mathrm{Mo}(\mathrm{CO})_{5}$ ] contain the intact four ring whereas in $\left[t-\mathrm{Bu}_{3} \mathrm{Sb}_{4} \mathrm{MoC}_{5} \mathrm{Me}_{5}\right]$ one tert-butyl group is replaced by an transition metal substituent. ${ }^{40}$

$(t-\mathrm{BuSb})_{4}$ reacts with $\left[\mathrm{C}_{5} \mathrm{R}_{5} \mathrm{Mo}(\mathrm{CO})_{3}\right]_{2}(\mathrm{R}=\mathrm{H}$, $\mathrm{Me})$ to form the tetrahedrane derivatives $\left[\mathrm{C}_{5} \mathrm{H}_{5}\left\{(\mathrm{CO})_{2} \mathrm{Mo}_{2} \mathrm{Sb}_{2}\right], \quad\left[\mathrm{C}_{5} \mathrm{H}_{5}(\mathrm{CO})_{2} \mathrm{MoSb}_{3}\right]\right.$ and $\left[\mathrm{C}_{5} \mathrm{Me}_{5}(\mathrm{CO})_{2} \mathrm{MoSb}_{3}\right]^{41}$ Also a remarkable tripledecker complex with the cyclo-Sb $b_{5}$ ligand, $[(t-$ $\left.\left.\mathrm{Bu}_{3} \mathrm{C}_{5} \mathrm{H}_{2}\right) \mathrm{Mo}\left(\mathrm{Sb}_{5}\right) \mathrm{Mo}\left(t-\mathrm{Bu}_{2} \mathrm{MeC}_{5} \mathrm{H}_{2}\right)\right]$, was reported. ${ }^{42}$

Another synthetic application of $(t-\mathrm{BuSb})_{4}$ is the use of the ring for reactions with alkali metals. With potassium the trinuclear antimonide $[\{(t-$ $\left.\left.\mathrm{Bu})_{2} \mathrm{Sb}\right\}_{2} \mathrm{Sb}\right]^{-}$is formed. It can be crystallized as $\mathrm{K}$ (pmdeta $)_{2}$ salt (pmdeta = pentamethyldiethylenetriamine) ${ }^{43}$ Reactions of the four membered 
ring with sodium or potassium lead to the antimonides $\left[\mathrm{M}(\text { pmdeta })_{n}\right]\left[\left(t-\mathrm{Bu}_{2} \mathrm{Sb}\right)_{2} \mathrm{Sb}\right](\mathrm{M}=\mathrm{Na}$, $\mathrm{K} ; n=1,2)$ and $\{[\mathrm{K}($ pmdeta $)][\mathrm{Sb}(t-\mathrm{Bu}) \mathrm{Sb}(t-$ $\left.\left.\mathrm{Bu})_{2}\right]\right\}_{2} .{ }^{44}$ With $\mathrm{M}=\mathrm{Li}$, Na, or $\mathrm{K}$, were obtained $\left[\mathrm{Li}(\text { tmeda })_{2}\right]\left[\left\{(t-\mathrm{Bu})_{2} \mathrm{Sb}\right\}_{2} \mathrm{Sb}\right]$ (tmeda $=$ tetramethylethylenediamine), $\quad[\mathrm{Na}(\mathrm{tmeda})(\mathrm{thf})][\{(t-$ $\left.\left.\mathrm{Bu})_{2} \mathrm{Sb}\right\}_{2} \mathrm{Sb}\right]$ and $[\mathrm{K}($ pmdeta $)]\left[(t-\mathrm{Bu})_{2} \mathrm{Sb}\right]$, respectively. ${ }^{45}$ NMR studies revealed that in the reactions of potassium in tetrahydrofuran the anions $\left[\left\{(t-\mathrm{Bu})_{2} \mathrm{Sb}\right\}_{2} \mathrm{Sb}\right]^{-},\left[(t-\mathrm{Bu})_{2} \mathrm{Sb}(t-\mathrm{Bu}) \mathrm{Sb}\right]^{-}$and $\left[(t-\mathrm{Bu})_{2} \mathrm{Sb}\right]^{-}$are formed successively.

The main role of the tert-butyl group in organoantimony(I) chemistry is to stabilize the four membered ring all-trans- $(t-\mathrm{BuSb})_{4}$, a key compound in the field of organoantimony(I) chemistry, which is relatively stable, has a strong tendency of formation and is a useful reagent. The tert-butylantimony four membered ring can be isolated both by crystallization and by sublimation and can be used as reagent in transition metal chemistry as intact ring, as ring fragment, or as source of $\mathrm{Sb}_{2}, \mathrm{Sb}_{3}$, or $\mathrm{Sb}_{5}$ ligands. Equally important is the use as reagent for the formation of alkali metal salts or complexes with trinuclear, binuclear and mononuclear tert-butylantimony anions. There is also a five membered tert-butyl antimony ring which requires a cis arrangement of two $t$ - $\mathrm{Bu}$ groups and therefore is less favorable. Between the five and the four ring there is no ringring equilibrium. A tert-butyl antimony chain was not reported.

\section{THE}

\section{PENTAMETHYLCYCLOPENTADIENYL ANTIMONY(I) SYSTEM \\ AND A POLYCYCLIC ALL-CIS-CYCLO- TRISTIBANE WITH THE $\mathrm{MeC}\left(\mathrm{CH}_{2}\right)_{3}$ LIGAND}

A special substituent in organoantimony(I) chemistry is the pentamethylcyclopentadienyl group, $\left(\mathrm{R}=\mathrm{Me}_{5} \mathrm{C}_{5}\right)$ which stabilizes an antimony four ring in the crystalline state and monomeric $\mathrm{RSb}$ molecules in solution. ${ }^{46}$ Pentamethylcyclopentadienylantimony is formed by a reaction of $\mathrm{SbCl}_{3}$ with $\mathrm{RK}\left(\mathrm{R}=\eta^{1}-\mathrm{Me}_{5} \mathrm{C}_{5}\right)$ in etheral solution at -78 ${ }^{\circ} \mathrm{C}$ giving dimeric pentamethylcyclopentadiene and orange-red $(\mathrm{RSb})_{4}$ in high yield. The tetrameric, folded ring structure was determined by a singlecrystal structure determination. Contrary to the solid state structure, monomeric molecules, $\eta^{5}-\mathrm{Me}_{5} \mathrm{C}_{5}-\mathrm{Sb}$ are found in benzene and hexane solutions. The monomers were characterized by cryoscopic determinations of the molecular mass and by NMR spectra showing a singlet signal for the protons of the methyl groups and two ${ }^{13} \mathrm{C}$ resonance signals, one for the carbon atoms in the methyl groups and one for the carbon atoms of the $\mathrm{C}_{5}$-ring. Pentamethylcyclopentadienylantimony can be used in the preparative chemistry as source of $\mathrm{Sb}_{4}$ units in complexes of magnesium or gallium. ${ }^{47}$

The role of the pentamethylcyclopentadienyl group which is bonded in the $\eta^{1}$-mode through a $\mathrm{Sb}-\mathrm{C}$ sigma bond is to exert sterical protection on the antimony centers. The pentamethylcyclopentadienylantimony(I) system is extraordinary not because a four membered antimony ring is stabilized but because this ring dissociates in solution with formation of monomeric units. Such a behavior is unique in the chemistry of antimony rings. In the monomer the pentamethylcyclopentadienyl group is coordinated in the $\eta^{5}$ - mode and therefore can be considered as a five electron donor ligand. $\left[\eta^{5}-\mathrm{Me}_{5} \mathrm{C}_{5} \mathrm{Sb}\right]$ is a ten electron species where five electrons stem from the organic group and five from the antimony atom in contrast to $\left[\eta^{1}-\mathrm{Me}_{5} \mathrm{C}_{5} \mathrm{Sb}\right]$ and all the other $\mathrm{RSb}$ species which are six electron species and therefore tend to form oligomers.

Another unusual organic group for $\mathrm{Sb}(\mathrm{I})$ species is the tridentate $\mathrm{MeC}\left(\mathrm{CH}_{2}\right)_{3}$ ligand, which stabilizes a $\mathrm{Sb}_{3}$ ring. Reduction of $\mathrm{MeC}\left(\mathrm{CH}_{2} \mathrm{SbCl}_{2}\right)_{3}$ with sodium in tetrahydrofuran gives $\mathrm{MeC}\left(\mathrm{CH}_{2} \mathrm{Sb}\right)_{3}$, a tristibane with the cis arrangement of the $\mathrm{Sb}-\mathrm{C}$ bonds enforced by the polycycyclic system. In the crystal the molecules are arranged to chains and layers through close intermolecular $\mathrm{Sb} \cdots \mathrm{Sb}$ contacts, shorter than the sum of van der Waals radii of two antimony atoms, which is $4.12 \AA^{48}{ }^{48}$

The three ring forms $\left[\mathrm{MeC}\left(\mathrm{CH}_{2} \mathrm{Sb}\right)_{3} \mathrm{M}(\mathrm{CO})_{5}\right]$ complexes with $\left[\mathrm{M}(\mathrm{CO})_{5}(\mathrm{thf})\right](\mathrm{M}=\mathrm{Cr}, \mathrm{Mo}$, W). ${ }^{49,50}$

\section{PHENYLANTIMONY(I) COMPOUNDS}

Phenyl antimony(I) compounds were studied since the beginning of the $20^{\text {th }}$ century in the context of the famous aryl arsenic medicine for syphilis, salvarsan. It was hoped that arylantimony(I) compounds should have similar therapeutic effects. At the time for phenyl antimony and other aryl antimony(I) compounds formulas with a double bond $\mathrm{RSb}=\mathrm{SbR}$ were used, but later it came out that all the earlier described compounds are more or less well 
defined polymers. Such a polymer, $(\mathrm{PhSb})_{x}$ was reported by Schmidt in 1920 as air sensitive brown to black powder, formed by reaction of $\mathrm{PhSbO}$ with sodium hypophosphite. ${ }^{15}$ A similar polymer was obtained by reaction of phenylstibonic acid, $\mathrm{PhSbO}_{3} \mathrm{H}_{2}$ with zinc amalgam. ${ }^{51}$ Later it was stated that the analytical values for these polymers lie between $(\mathrm{PhSb})_{x}$ and $\mathrm{Sb}^{52}$ Polymeric materials with analytical values for antimony somewhat too low for the formula $(\mathrm{PhSb})_{x}$ were obtained by thermal decomposition of $\mathrm{PhSbH}_{2}$ with evolution of hydrogen, or by decomposition of $\mathrm{Ph}_{2} \mathrm{SbH}^{53}$ Also the reaction of $\mathrm{PhSbH}_{2}$ with $\mathrm{PhSbI}_{2}$ gave a black polymeric material. ${ }^{54} \mathrm{~A}$ black powder with the analytical data supporting the formula $\mathrm{Cl}\left(\mathrm{C}_{6} \mathrm{H}_{5} \mathrm{Sb}\right)_{15} \mathrm{Cl}$ was obtained from $\mathrm{PhSbCl}_{2}$ and $\mathrm{Ph}_{2} \mathrm{SiH}_{2}{ }^{55}$ A mixture of $(\mathrm{PhSb})_{x}$ and $\mathrm{Sb}$ obtained from $\mathrm{PhSbH}_{2}$ and $n$-BuLi was reported by Issleib and Balszuweit, ${ }^{56}$ and also the reduction of $\mathrm{PhSbBr}_{2}$ with $\mathrm{Mg}$ in gave a polymeric material that was described as $(\mathrm{PhSb})_{x} \cdot{ }^{57}$ The first syntheses of a phenylantimony ring, $(\mathrm{PhSb})_{6} \cdot \mathrm{C}_{6} \mathrm{H}_{6}$ was performed by Issleib and Balszuweit. This ring compound was obtained as yellow orange crystals stable in air. ${ }^{58}$ In the synthetic reaction the styrene is transformed into ethyl benzene probably through a radical mechanism. The formation of $(\mathrm{PhSb})_{6}$ can occur stepwise or with the monomer $\mathrm{PhSb}$ as intermediate.

Single crystals of $(\mathrm{PhSb})_{6} \cdot \mathrm{C}_{6} \mathrm{D}_{6}$ were first obtained serendipitously in an NMR tube filled with a solution of $\mathrm{PhSb}\left(\mathrm{SiMe}_{3}\right)_{2}$ in $\mathrm{C}_{6} \mathrm{D}_{6}$ that was exposed to very slow access of air. In an analogous way also other solvates of the phenyl antimony six ring with cyclohexane, 1,4-dioxane, benzene, toluene were obtained and characterized by X-ray crystallography. ${ }^{59-60}$ In the crystals of $(\mathrm{PhSb})_{6}$ solvates there are $\mathrm{Sb}_{6}$ chairs with equatorial phenyl groups. The rings form stacks of $(\mathrm{PhSb})_{6}$ molecules with short intermolecular $\mathrm{Sb} \cdots \mathrm{Sb}$ interactions. The solvent molecules fill gaps in the structures. The six ring is not very soluble. In contrast to the air stable crystals, the solutions in $\mathrm{C}_{6} \mathrm{D}_{6}$ are air sensitive. They are obtained in sealed NMR tubes after prolonged moderate heating. ${ }^{1} \mathrm{H}-\mathrm{NMR}$ spectra of solutions show the presence of the five and four membered rings $(\mathrm{PhSb})_{n}(n=4,5)$. The phenylantimony rings were also obtained in NMR tube experiments in $\mathrm{C}_{6} \mathrm{D}_{6}$ by reaction of $\mathrm{Cp}_{2} \mathrm{Co}$ and $\mathrm{PhSbCl}_{2}{ }^{61}$ The equilibria are shown in Scheme 4.

The role of the phenyl group is to stabilize both polymers $(\mathrm{PhSb})_{x}$ and rings $(\mathrm{PhSb})_{n}(n=4-6)$. Phenyl groups are firmly bonded to antimony and exert a moderate sterical protection. In the crystal there are phenyl antimony six membered rings, which are very stable, not only thermally, but also towards oxygen of the air. Such a behavior is rare for antimony compounds with $\mathrm{Sb}-\mathrm{Sb}$ bonds. The six rings are unstable in solution where they form equilibrium mixtures of five and four rings. ${ }^{62} \mathrm{On}$ dilution the proportion of the four rings is increasing on the cost of the five rings as expected according to the principle of Le Chatelier. In contrast to the well characterized six membered rings, the structures of the polymeric forms of phenyl antimony are unknown. Coordination compounds with phenylantimony(I) ligands include the distibene complex $\left[(\mathrm{PhSb})_{2}\left\{\mathrm{~W}(\mathrm{CO})_{5}\right\}_{3}\right],{ }^{63}$ and a monomeric phenylantimony(phenylstibinidene) moiety stabilized as carbene complex. ${ }^{64}$ The structure of the latter is shown in Figure 1.

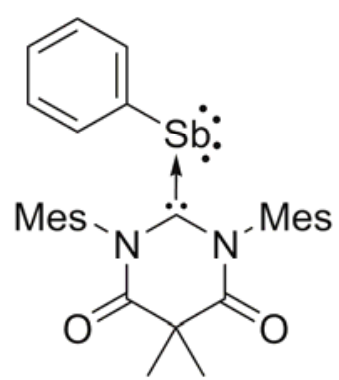

Fig. 1 - A carbene complex of phenyl stibinidene.

\section{TOLYLANTIMONY RINGS}

In a way analogous to the syntheses of phenyl antimony hexamers also crystalline samples of ortho-, meta-, and para-tolyl antimony cyclohexamers were formed by reaction of the corresponding tolyl(bistrimethylsilyl)stibanes with traces of air. The molecular structures of the hexamers $(m \text {-TolSb })_{6}$ and $(o \text {-TolSb })_{6}$ were determined by single-crystal X-ray diffraction. The tolyl antimony rings crystallize without solvent molecules. The crystals consist of stacks of $(\mathrm{RSb})_{6}$ $(\mathrm{R}=o$-Tol, $m$-Tol, $p$-Tol) rings in the chair conformation with equatorial tolyl substituents. In $\mathrm{C}_{6} \mathrm{D}_{6}$ solutions there are ring-ring equilibria between the pentamer and the tetramer. In saturated solutions $88 \%$ of the tolyl groups belong to the pentamer and $12 \%$ to the tetramer. According to the principle of Le Chatelier the proportion of the tetramer increases with dilution. The tolylantimony rings were also obtained in NMR tube experiments in $\mathrm{C}_{6} \mathrm{D}_{6}$ by reaction of $\mathrm{Cp}_{2} \mathrm{Co}$ and $\mathrm{RSbCl}_{2}{ }^{6}{ }^{6}$ 


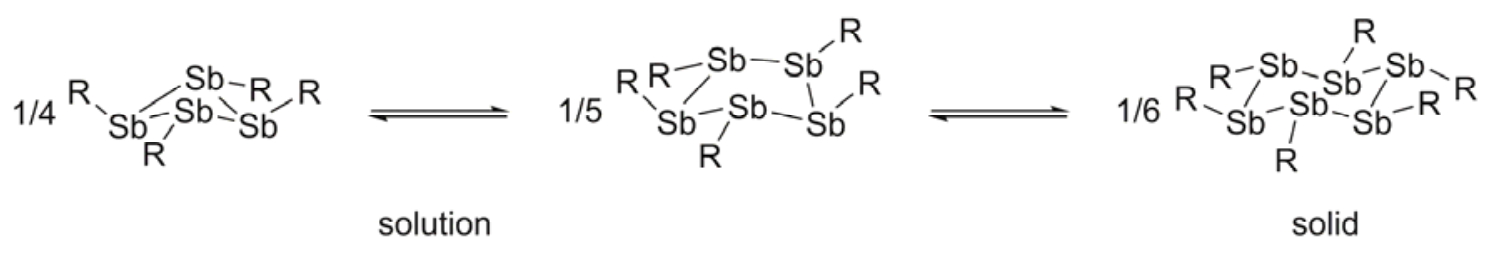

Scheme 4 - Equilibria in the phenylantimony system.

It is not surprising that the role of the tolyl substituents in organoantimony(I) chemistry is similar to that of the phenyl group. The tolyl antimony ring systems consist of six membered rings in the solid and five- as well as fourmembered rings in solution. It can be assumed that better packing of the six rings is responsible for the preference of hexamers in the crystal. It is very likely that also polymeric forms of tolylantimony(I) compounds might be formed be reduction of tolyl antimony dihalides, but they were not reported.

\section{THE MESITYLANTIMONY FOUR MEMBERED RING}

The mesityl substituent, 2,4,6- $\mathrm{Me}_{3} \mathrm{C}_{6} \mathrm{H}_{2}$ (Mes) exerts sterical protection through two methyl groups in ortho position of the aromatic ring higher than the sterical influence of the phenyl and tolyl groups. The higher sterical protection leads to the preference for the ring size to four. (MesSb) ${ }_{4}$ is the sole product obtained by reaction of $\mathrm{MesSbBr}_{2}$ with magnesium in tetrahydrofuran. Crystals of $(\mathrm{MesSb})_{4}$ solv $(\mathrm{solv}=$ benzene, toluene) are obtained from the respective solvent. ${ }^{65}$ The ring is stable in solution. No ring-ring equilibrium is observed. The analysis of the crystal structure of (MesSb $)_{4}$ 'benzene reveals the presence of the four member ring with the mesityl groups in trans positions. ${ }^{1}$ The rings are weakly associated to chains through $\mathrm{Sb} \cdots \mathrm{Sb}$ contacts. The planar geometry of the mesityl group favors the four membered ring with the all trans arrangement of the organic groups. In this respect there are similarities with the tert-butyl and the bis(trimethylsilyl)methyl groups. The mesityl antimony tetramer is easily available. The potential of this ring as a reagent has not been investigated yet.

\section{ANTIMONY(I) COMPOUNDS WITH TERPHENYL SUBSTITUENTS}

Spacious protecting groups are the metaterphenyl groups that were used by Power et al. to stabilize the dimers $(\mathrm{RSb})_{2}$ which are known as distibenes $\mathrm{RSb}=\mathrm{SbR}$ and possess antimonyantimony double bonds. ${ }^{66}$ One of the metaterphenyl groups used is the 2,6-dimesitylphenyl substituent $\left(\mathrm{R}=2,6-\mathrm{Mes}_{2} \mathrm{C}_{6} \mathrm{H}_{3}, \quad\right.$ Mes $=2,4,6-$ $\mathrm{Me}_{3} \mathrm{C}_{6} \mathrm{H}_{2}$ ) where two bulky mesityl groups are in the ortho positions of a phenyl group, the other the 2,6-Trip ${ }_{2} \mathrm{C}_{6} \mathrm{H}_{2}$ group[Trip $=2,4,6-(i-\mathrm{Pr})_{3} \mathrm{C}_{6} \mathrm{H}_{2}$ or triisopropylphenyl]. The structure of these groups are shown in Fig. 2.

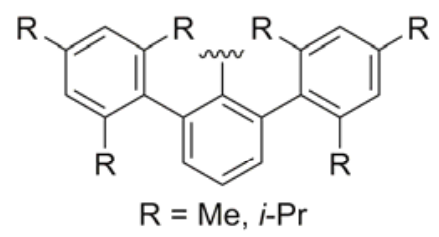

Fig. 2 - Structural formulae of meta-terphenyl groups.

The distibenes display high thermally stability. They are formed by reaction of $\mathrm{RSbCl}_{2}$ with potassium or potassium graphite. A tungsten carbonyl complexes with the distibene ligand, $\mathrm{W}(\mathrm{CO})_{5}(\mathrm{RSbSbR}) \quad\left(\mathrm{R}=2,6-\mathrm{Mes}_{2} \mathrm{C}_{6} \mathrm{H}_{3}\right)$ was obtained from a solution of $\left(\mathrm{RSbH}_{2}\right) \mathrm{W}(\mathrm{CO})_{5}$ in toluene on exposure to day light. The titanium complex $\mathrm{Cp}_{2} \mathrm{Ti}(\mathrm{RSbSbR})\left(\mathrm{R}=2,6-\mathrm{Mes}_{2} \mathrm{C}_{6} \mathrm{H}_{3}\right)$ was formed from $\mathrm{RSbH}_{2}$ and $\mathrm{Cp}_{2} \mathrm{Ti}\left[\left(\mathrm{Me}_{3} \mathrm{Si}_{2} \mathrm{C}_{2}\right]\right.$. ${ }^{67}$

The role of the meta-terphenyl groups is to stabilize dimers and to hinder them to oligomerize to form rings. It is of historic interest that the old idea that arylantimony(I) compounds should have double bonds became true with the help of spacious 2,6-dimesityl phenyl groups.

The 2,6-dimesitylphenyl group is also useful for the stabilization of a tristibane $\mathrm{RSb}\left(\mathrm{SbMe}_{2}\right)_{2}(\mathrm{R}=$ 2,6- $\mathrm{Mes}_{2} \mathrm{C}_{6} \mathrm{H}_{3}$ ) and to hinder it sterically from decomposition into antimony cycles and tetramethyldistibane. This type of reaction was observed in the case of sterically less protected distibanes. The tristibane was obtained from $\mathrm{RSbH}_{2}$ and $\left(\mathrm{Me}_{2} \mathrm{Sb}\right)_{2}{ }^{68}$

\section{ANTIMONY(I) COMPOUNDS WITH THE BBT AND TBT GROUPS}

Substituents that stabilize distibenes, $\mathrm{RSb}=\mathrm{SbR}$ are not only terphenyl groups but also the phenyl 
derivatives $\left[\mathrm{R}=2,4,6-\left\{\mathrm{CH}\left(\mathrm{SiMe}_{3}\right)_{2}\right\}_{3} \mathrm{C}_{6} \mathrm{H}_{2}\right.$ (Tbt) and 2,6- $\left\{\mathrm{CH}\left(\mathrm{SiMe}_{3}\right)_{2}\right\}_{2}-4-\mathrm{C}\left(\mathrm{SiMe}_{3}\right)_{2} \mathrm{C}_{6} \mathrm{H}_{2}$ (Bbt)] used by Okazaki, Tokitoh, and co-workers. ${ }^{7,} 69-70$ The structures of Tbt and Bbt are showed in Fig. 3. $\mathrm{RSb}=\mathrm{SbR}(\mathrm{R}=\mathrm{Tbt})$ is formed by deselenation of $(\mathrm{RSbSe})_{3}$ or by dimerisation of the stibinidene intermediate $\mathrm{RSb}$, formed by a retro cycloaddition of the stibolene $\mathrm{RSb}\left(\mathrm{CH}_{2}\right)_{2} \mathrm{CH}=\mathrm{CMe} . \mathrm{RSb}=\mathrm{SbR}(\mathrm{R}$ $=\mathrm{Tbt})$ reacts with $\mathrm{Br}_{2}$ or $\mathrm{I}_{2}$ to form $\mathrm{RSbX}_{2}(\mathrm{X}=\mathrm{Br}$, I) with selenium to give (RSbSe $)_{3}$ and with oxygen to produce $(\mathrm{RSbO})_{2}$. $\mathrm{RSb}=\mathrm{SbR}(\mathrm{R}=\mathrm{Bbt})$ is obtained by reaction of $\mathrm{RSbBr}_{2}$ with magnesium in tetrahydrofuran. Electrochemical reduction or reaction of $\mathrm{RSb}=\mathrm{SbR}(\mathrm{R}=\mathrm{Bbt})$ with lithium gives the radical anion $\left[(\mathrm{RSb})_{2}\right]^{-70}$<smiles>[R]c1cc(C(C)C)c(C(C)C)c(C(C)C)c1</smiles>

Bbt: $\mathrm{R}=\left(\mathrm{Me}_{3} \mathrm{Si}\right)_{3} \mathrm{C}$

Tbt: $\mathrm{R}=\left(\mathrm{Me}_{3} \mathrm{Si}\right)_{2} \mathrm{CH}$

Fig. 3 - Structural formulae of Bbt and Tbt.

\section{ANTIMONY RINGS WITH ONE ARM $C, N$-LIGANDS}

A ligand with one pendant arm is the 2-dimethylaminomethylphenyl group which can act as bidentate $C, N$-ligand offering protection through the aryl ring and through the amino group. Reduction of $\mathrm{RSbCl}_{2}\left[\mathrm{R}=2-\left(\mathrm{Me}_{2} \mathrm{NCH}_{2}\right) \mathrm{C}_{6} \mathrm{H}_{4}\right]$ with $\mathrm{Mg}$ gives the four membered ring $(\mathrm{RSb})_{4}$. The ring inserts oxygen or sulfur to give the heterocycles $(\mathrm{RSbE})_{n}(\mathrm{E}=\mathrm{O}, n=3 ; \mathrm{E}=\mathrm{S}, n=2)$. It is remarkable that in the heterocycles the number of $\mathrm{RSb}$ groups is smaller than in the parent antimony four ring. With $\left[\mathrm{W}(\mathrm{CO})_{5}(\right.$ thf $\left.)\right]$ the monomeric $\mathrm{RSb}$ unit is trapped and the stibinidene complex $\left[\mathrm{RSb}\left\{\mathrm{W}(\mathrm{CO})_{5}\right\}_{2}\right]$ is formed. ${ }^{71}$ The structure of the stibinidene complex is shown in Fig. 4.

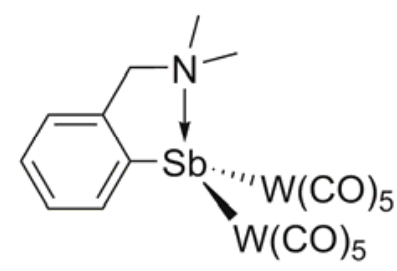

Fig. 4 - Structure of [2-( $\left.\left.\mathrm{Me}_{2} \mathrm{NCH}_{2}\right) \mathrm{C}_{6} \mathrm{H}_{4} \mathrm{Sb}\left\{\mathrm{W}(\mathrm{CO})_{5}\right\}_{2}\right]$.
Due to the effects of the pendant group the 2-dimethylaminomethylphenyl group is an excellent ligand for the stabilization of antimony four rings, for $\mathrm{Sb}, \mathrm{O}$ and $\mathrm{Sb}, \mathrm{S}$-heterocycles and for complexes with the stibinidene ligand.

With the ketimino phenyl group $[\mathrm{R}=2$ $\left.\left(\mathrm{R}^{\prime} \mathrm{N}=\mathrm{CH}\right) \mathrm{C}_{6} \mathrm{H}_{4}, \quad \mathrm{R}^{\prime}=2,6-(i-\operatorname{Pr})_{2} \mathrm{C}_{6} \mathrm{H}_{3}\right]$ which contains in ortho position of a phenyl substituent one ketimino arm with a bulky aryl group a four membered all-trans ring $(\mathrm{RSb})_{4}$ is stabilized. The ring is formed by reaction of $\mathrm{RSbCl}_{2}$ with $\mathrm{K}[\mathrm{B}(s-$ $\left.\mathrm{Bu})_{3} \mathrm{H}\right]$. It is a folded antimony four ring with all the nitrogen atoms coordinated on antimony. ${ }^{72}$

\section{ANTIMONY(I) COMPOUNDS WITH SUBSTITUENTS CONTAINING TWO PENDANT ARMS}

The substituent $\mathrm{R}=2,6-\left(\mathrm{Me}_{2} \mathrm{NCH}_{2}\right)_{2} \mathrm{C}_{6} \mathrm{H}_{3}$ is able to act as tridentate $N, C, N$-ligand. Antimony homocycles with this ligand were obtained by reduction of $\mathrm{RSbCl}_{2}$ with $\mathrm{K}\left[\mathrm{B}(i-\mathrm{Bu})_{3} \mathrm{H}\right]$. Two ring products, cyclo- $\mathrm{R}_{4} \mathrm{Sb}_{4}$ and $\mathrm{R}_{3} \mathrm{Sb}_{5}$ were obtained. cyclo $-\mathrm{R}_{4} \mathrm{Sb}_{4}$ is a antimony four ring with all trans configuration of the R substituents where six of the eight nitrogen atoms are coordinated on antimony atoms. This means that two of the substituents act as tridentate $\mathrm{N}, \mathrm{C}, \mathrm{N}$-ligands and two as bidentate $N, C$-ligands with a free dimethylamino group. ${ }^{73}$

The bis(ketimino)phenyl group $[\mathrm{R}=2,6$ $\left.\{\mathrm{R} \prime \mathrm{N}=\mathrm{C}(\mathrm{Me})\}_{2} \mathrm{C}_{6} \mathrm{H}_{3}, \mathrm{R}^{\prime}=2,6-\mathrm{Me}_{2} \mathrm{C}_{6} \mathrm{H}_{3}\right]$ acts as $N, C, N$-pincer ligand and stabilizes the stibinidene $\mathrm{RSb}^{73}$ The stibinidine was obtained by reduction of $\mathrm{RSbCl}_{2}$ with $\mathrm{K}\left[\mathrm{B}(i-\mathrm{Bu})_{3} \mathrm{H}\right]$. In the stibinidene molecule the $\mathrm{Sb}$ atom is encapsulated in the ligand cavity. The monomeric structure is stabilized by donation of donor atom electron density to the empty $p$ orbital of the antimony atom. One $p$-orbital of $\mathrm{Sb}$ is used for the $\mathrm{Sb}-\mathrm{C} \sigma$ bond. One $s$ orbital and one $p$ orbital are used for the two lone pairs of the stibinidene. The empty $p$ orbital in the plane of the central aryl group of the ligand interacts with the $\mathrm{N}$ atoms. Also the reduction of $\mathrm{RSbCl}_{2}\left[\mathrm{R}=2,6-(\mathrm{R} \prime \mathrm{N}=\mathrm{CH})_{2} \mathrm{C}_{6} \mathrm{H}_{3}, \mathrm{R}^{\prime}=\mathrm{Ph}, t-\mathrm{Bu}\right.$, 2,6- $\left.(i-\mathrm{Pr})_{2} \mathrm{C}_{6} \mathrm{H}_{3}\right]$ with $\mathrm{KC}_{8}, \mathrm{Li}\left[\mathrm{AlH}_{4}\right]$ or $\mathrm{K}[\mathrm{B}(s-$ $\left.\mathrm{Bu})_{3} \mathrm{H}\right]$ leads to stibinidenes. ${ }^{74}$ Formulae of reported stibinidenes are shown in Fig. 5.

The stibinidene $\mathrm{RSb}[\mathrm{R}=2,6-(t-$ $\mathrm{BuN}=\mathrm{CH})_{2} \mathrm{C}_{6} \mathrm{H}_{3}$ ] reacts with sulfur or selenium to form $\mathrm{RSbE}\left(\mathrm{E}=\mathrm{S}\right.$, Se) and with $\mathrm{E}_{2} \mathrm{Ph}_{2}$ to form $\mathrm{RSb}(\mathrm{ER})_{2}(\mathrm{E}=\mathrm{S}, \mathrm{Se}){ }^{75}$ Also stibinidene complexes $\left[\mathrm{RSbM}(\mathrm{CO})_{5}\right](\mathrm{M}=\mathrm{Cr}, \mathrm{Mo}, \mathrm{W})$, and $\mathrm{RSbFe}(\mathrm{CO})_{4}$ were prepared by reactions of $\mathrm{RSb}[\mathrm{R}=2,6-(t-$ $\left.\mathrm{BuN}=\mathrm{CH})_{2} \mathrm{C}_{6} \mathrm{H}_{3}\right]$ with appropriate metal carbonyl 
complexes. ${ }^{76}$ The reaction between $\mathrm{RSb}[\mathrm{R}=2,6$ $\left.(t-\mathrm{BuN}=\mathrm{CH})_{2} \mathrm{C}_{6} \mathrm{H}_{3}\right]$ and $\quad\left[\mathrm{Co}_{2}(\mathrm{CO})_{8}\right]$ or $\left[\mathrm{Mn}_{2}(\mathrm{CO})_{10}\right]$ gave ionic compounds $\left[(\mathrm{RSb})_{2} \mathrm{Co}(\mathrm{CO})_{3}\right]^{+}\left[\mathrm{Co}(\mathrm{CO})_{4}\right]^{-}$and

$\left[(\mathrm{RSb})_{2} \mathrm{Mn}(\mathrm{CO})_{4}\right]^{+}\left[\mathrm{Mn}(\mathrm{CO})_{5}\right]^{-77}$. Also rhodium or iridium complexes with stibinidene ligands, $\mathrm{RSbM}(\mathrm{Cl})(\operatorname{cod}) \quad[\mathrm{M}=\mathrm{Rh}, \quad \mathrm{Ir} ; \mathrm{R}=2,6-(t-$ $\mathrm{BuN}=\mathrm{CH})_{2} \mathrm{C}_{6} \mathrm{H}_{3}$, cod = 1,5-cyclooctadiene] were reported. $^{78}$
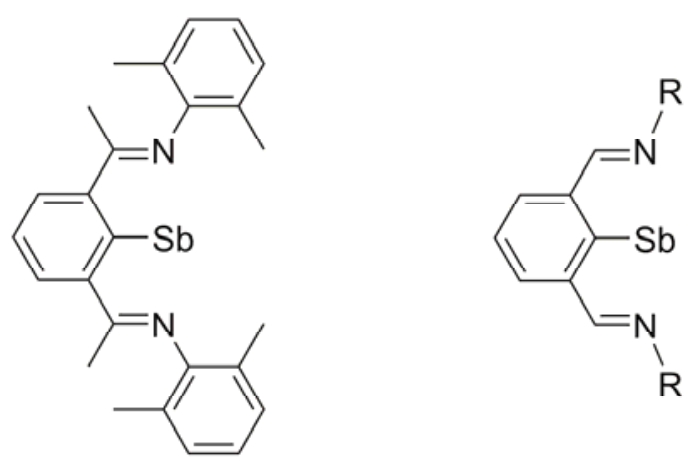

Fig. 5 - Stibinidenes stabilized with bis(ketimino)phenyl substituents $\left[\mathrm{R}=\mathrm{Ph}, t-\mathrm{Bu}, 2,6-(i-\mathrm{Pr})_{2} \mathrm{C}_{6} \mathrm{H}_{3}\right]$.

These studies show that the stable stibinidenes $\mathrm{RSb}$ with bis(ketimino)phenyl substituents are valuable two electron donor ligands in transition metal chemistry.

\section{OVERVIEW OF THE ROLE OF THE GROUPS R ON THE CONSTITUTION OF RSB(I) COMPOUNDS}

Not surprisingly the general trend in RSb chemistry is the preference of smaller molecules with the increasing size and sterical demands of the $\mathrm{R}$ group. This trend is enhanced when the $\mathrm{R}$ group contains additional pendant amino or ketimino groups. Methyl groups stabilize a solid polymer $(\mathrm{RSb})_{x}$. Ethyl, n-propyl, isopropyl, and $n$-butyl groups favor five and four membered rings $(\mathrm{RSb})_{n}$ $(n=4,5)$ in solution (in $\left.\mathrm{C}_{6} \mathrm{D}_{6}\right)$ and polymeric chains (RSb) $)_{x}$ in the solid state. The isobutyl group supports the formation of four and five rings in equilibria. Stable five rings $(\mathrm{RSb})_{5}$ with known crystal structures are formed with $\mathrm{R}=\mathrm{Me}_{3} \mathrm{CCH}_{2}$ and $\mathrm{Me}_{3} \mathrm{SiCH}_{2}$. Phenyl- and tolyl groups favor the formation of six membered rings in the solid state and four and five membered rings in solution. The sterically more demanding groups $\mathrm{R}=t$ - $\mathrm{Bu}$, $\left(\mathrm{Me}_{3} \mathrm{Si}\right)_{2} \mathrm{CH}, \quad 2,4,6-\mathrm{Me}_{3} \mathrm{C}_{6} \mathrm{H}_{2}, \quad \mathrm{Me}_{5} \mathrm{C}_{5}$, and the chelating ligands $\mathrm{R}=2-\left(\mathrm{Me}_{2} \mathrm{NCH}_{2}\right) \mathrm{C}_{6} \mathrm{H}_{4}, 2,6-$ $\left(\mathrm{Me}_{2} \mathrm{NCH}_{2}\right)_{2} \mathrm{C}_{6} \mathrm{H}_{3}, 2-\left\{2,6-(i-\mathrm{Pr})_{2} \mathrm{C}_{6} \mathrm{H}_{3} \mathrm{~N}=\mathrm{CH}\right\} \mathrm{C}_{6} \mathrm{H}_{3}$, favor cyclo-tetramers $(\mathrm{RSb})_{4}$ in the all-trans configuration, stable in solution and in the solid state. It is remarkable how many chemically and sterically quite different groups are able to favor four rings. With $\mathrm{R}=\left(\mathrm{Me}_{3} \mathrm{Si}\right)_{2} \mathrm{CH}$ also a unique cyclo-trimer $(\mathrm{RSb})_{3}$ is known. Phenyl derivatives with bulky substituents in the ortho positions, 2,6$\mathrm{R}_{2} \mathrm{C}_{6} \mathrm{H}_{3}\left[\mathrm{R}=\left(\mathrm{Me}_{3} \mathrm{Si}\right)_{2} \mathrm{CH}, 2,4,6-\mathrm{Me}_{3} \mathrm{C}_{6} \mathrm{H}_{2}\right]$ and similar groups stabilize dimers $(\mathrm{RSb})_{2}$. The stabilization of monomers RSb was achieved with phenyl groups bearing two pendant ketimino arms like $\mathrm{R}=2,6-\left(\mathrm{R}^{\prime} \mathrm{N}=\mathrm{CH}\right)_{2} \mathrm{C}_{6} \mathrm{H}_{3}\left[\mathrm{R}^{\prime}=\mathrm{Ph}, t-\mathrm{Bu}, 2,6-(i-\right.$ $\left.\operatorname{Pr})_{2} \mathrm{C}_{6} \mathrm{H}_{3}\right]$ and related ligands.

Acknowledgements. The author is grateful to Professors Anca and Cristian Silvestru from the Babeş-Bolyai University and to all colleagues and coworkers that contributed to the research in the field of organoantimony(I) compounds.

\section{REFERENCES}

1. M. Ateş, H. J. Breunig, S. Güleç, W. Offermann, K. Häberle and M. Dräger, Chem. Ber., 1989, 122, 473.

2. H. J. Breunig, Main Group Met. Chem., 1993, 16, 143.

3. S. Patai, The chemistry of organic arsenic, antimony and bismuth compounds. John Wiley \& Sons: Chichester, 1994.

4. H. J. Breunig and R. Rösler, Coord. Chem. Rev., 1997, 163, 33.

5. C. Jones, Coord. Chem. Rev., 2001, 215, 151.

6. L. Balázs and H. J. Breunig, Coord. Chem. Rev., 2004, 248, 603.

7. N. Tokitoh, J. Organomet. Chem., 2000, 611, 217.

8. C. I. Rat, C. Silvestru and H. J. Breunig, Coord. Chem. Rev., 2013, 257, 818 .

9. M. Yoshifuji, J. Organomet. Chem., 2000, 611, 210.

10. G. van Koten, J. Organomet. Chem., 2017, 845, 4.

11. S. Schulz, Coordination Chemistry Reviews, 2001, 215, 1.

12. A. M. Christianson and F. P. Gabbaï, Main Group Strategies towards Functional Hybrid Materials, 2017, 405.

13. C. Löwig and E. Schweizer, Justus Liebigs Ann. Chem., 1850, 75, 315.

14. P. Ehrlich and P. Karrer, Ber. Dtsch. Chem. Ges., 1913, 46, 3564.

15. H. Schmidt, Justus Liebigs Ann. Chem., 1920, 421, 174.

16. A. L. Rheingold, Homoatomic rings chains and macromolecules of main-group elements. Elsevier: Amsterdam, 1977.

17. H. J. Breunig, M. Denker and K. H. Ebert, J. Organomet. Chem., 1994, 470, 87.

18. A. B. Burg and L. R. Grant, J. Am. Chem. Soc., 1959, 81, 1.

19. M. Ateş, H. J. Breunig, K. Ebert, S. Güleç, R. Kaller and M. Draeger, Organometallics, 1992, 11, 145.

20. H. J. Breunig, S. Gülec and R. Kaller, Phosphorus, Sulfur Silicon Relat. Elem., 1992, 64, 107.

21. G. Alonzo, N. Bertazzi, H. J. Breunig and K. H. Ebert, Hyperfine Interact., 1994, 90, 505.

22. Y. Mourad, Y. Mugnier, H. J. Breunig and M. Ateş, $J$. Organomet. Chem., 1991, 406, 323.

23. L. Balázs, G. Balázs, H. J. Breunig, I. Ghesner and E. Lork, Polyhedron, 2003, 22, 1719.

24. L. Balázs and H. J. Breunig, Organometallics, 2004, 23, 304.

25. G. Balázs, L. Balázs, H. J. Breunig and E. Lork, Organometallics, 2003, 22, 2919. 
26. A. Silvestru, H. J. Breunig, K. H. Ebert and R. Kaller, J. Organomet. Chem., 1995, 501, 117.

27. H. J. Breunig, I. Ghesner and E. Lork, Organometallics, 2001, 20, 1360.

28. G. Balázs, H. J. Breunig and E. Lork, Z. anorg. allg. Chem., 2001, 627, 1855.

29. G. Balázs, H. J. Breunig and E. Lork, Z. anorg. allg. Chem., 2003, 629, 1937.

30. H. J. Breunig and A. Soltani-Neshan, J. Organomet. Chem., 1984, 262, c27.

31. H. J. Breunig, R. Rösler and E. Lork, Organometallics, 1998, 17, 5594.

32. H. J. Breunig, R. Rösler and E. Lork, Angew. Chem. Int. Ed. Engl., 2003, 36, 2237.

33. G. Balázs, H. J. Breunig and E. Lork, Z. anorg. allg. Chem., 2003, 629, 637.

34. G. Balázs, H. J. Breunig, E. Lork and S. Mason, Organometallics, 2003, 22, 576.

35. K. Issleib, B. Hamann and L. Schmidt, Z. anorg. allg. Chem., 1965, 339, 298.

36. H. J. Breunig, Z. Naturforsch., B: Anorg. Chem., Org. Chem., 1978, 33, 242.

37. O. Mundt, G. Becker, H.-J. Wessely, H. J. Breunig and H. Kischkel, Z. anorg. allg. Chem., 1982, 486, 70.

38. H. J. Breunig and H. Kischkel, Z. anorg. allg. Chem., 1983, $502,175$.

39. H. J. Breunig and J. Pawlik, Z. anorg. allg. Chem., 1995, $621,817$.

40. H. J. Breunig, R. Rösler and E. Lork, Z. anorg. allg. Chem., 1999, 625, 1619.

41. H. J. Breunig, R. Rösler and E. Lork, Angew. Chem. Int. Ed. Engl., 1997, 36, 2819.

42. H. J. Breunig, N. Burford and R. Rösler, Angew. Chem. Int. Ed., 2000, 39, 4148.

43. H. Althaus, H. J. Breunig, J. Probst, R. Rösler and E. Lork, J. Organomet. Chem., 1999, 585, 285.

44. H. J. Breunig, M. E. Ghesner and E. Lork, J. Organomet. Chem., 2002, 660, 167.

45. H. J. Breunig, M. E. Ghesner and E. Lork, Z. anorg. allg. Chem., 2005, 631, 851.

46. T. F. Berlitz, S. Heike, L. Jörg and M. Ulrich, Z. Naturforsch., B: J. Chem. Sci., 1987, 43, 744.

47. C. Ganesamoorthy, J. Krüger, C. Wölper, A. S. Nizovtsev and S. Schulz, Chem. Eur. J., 2017, 23, 2461.

48. M. Mantina, A. C. Chamberlin, R. Valero, C. J. Cramer and D. G. Truhlar, J. Phys. Chem. A, 2009, 113, 5806.

49. J. Ellermann and A. Veit, J. Organomet. Chem., 1985, 290, 307.

50. J. Ellermann, E. Kock and H. Burzlaff, Acta Crystallogr., Sect. C: Cryst. Struct. Commun., 1985, 41, 1437.

51. L. Lequoq, J. Pharm. Belg., 1937, 19, 133.

52. F. Klages and W. Rapp, Chem. Ber., 1955, 88, 384.

53. W. Egon and N. Heinrich, Z. Naturforsch., B: Anorg. Chem., Org. Chem., 1957, 12, 125.
54. W. Egon and M. Kurt, Z. Naturforsch., B: Anorg. Chem., Org. Chem., 1957, 12, 127.

55. W. Kuchen and H. Ecke, Z. anorg. allg. Chem., 1963, 321, 138.

56. K. Issleib and A. Balszuweit, Z. anorg. allg. Chem., 1975, $418,158$.

57. H. J. Breunig and S. Tevfik, Z. Naturforsch., B: Anorg. Chem., Org. Chem., 1982, 37, 395.

58. K. Issleib and A. Balszuweit, Z. anorg. allg. Chem., 1976, $419,87$.

59. H. J. Breunig, K. Häberle, M. Dräger and T. Severengiz, Angew. Chem. Int. Ed. Engl., 1985, 24, 72.

60. H. J. Breunig, A. Soltani-Neshan, H. Karl and D. Martin, Z. Naturforsch., B: Anorg. Chem., Org. Chem., 1986, 41, 327.

61. H. J. Breunig, K. H. Ebert, J. Probst, Y. Mourad and Y. Mugnier, J. Organomet. Chem., 1996, 514, 149.

62. H. J. Breunig, K. H. Ebert, S. Gülec and J. Probst, Chem. Ber., 1995, 128, 599.

63. G. Huttner, U. Weber, B. Sigwarth and O. Scheidsteger, Angew. Chem. Int. Ed. Engl., 1982, 21, 215.

64. C. L. Dorsey, R. M. Mushinski and T. W. Hudnall, Chem. Eur. J., 2014, 20, 8914.

65. M. Ateş, J. Breunig H., A. Soltani-Neshan and M. Tegeler, Z. Naturforsch., B: Anorg. Chem., Org. Chem., 1986, 41, 321.

66. B. Twamley, C. D. Sofield, M. M. Olmstead and P. P. Power, J. Am. Chem. Soc., 1999, 121, 3357.

67. H. J. Breunig, T. Borrmann, E. Lork, C. I. Raț and U. Rosenthal, Organometallics, 2007, 26, 5364.

68. H. J. Breunig, E. Lork, O. Moldovan and C. I. Raț, J. Organomet. Chem., 2008, 693, 2527.

69. N. Tokitoh, Y. Arai, T. Sasamori, R. Okazaki, S. Nagase, H. Uekusa and Y. Ohashi, J. Am. Chem. Soc., 1998, 120, 433.

70. T. Sasamori, E. Mieda, N. Nagahora, K. Sato, D. Shiomi, T. Takui, Y. Hosoi, Y. Furukawa, N. Takagi, S. Nagase and N. Tokitoh, J. Am. Chem. Soc., 2006, 128, 12582.

71. L. M. Opris, A. Silvestru, C. Silvestru, H. J. Breunig and E. Lork, Dalton Trans., 2004, 3575.

72. L. Dostál, R. Jambor, A. Růžička and P. Šimon, Eur. J. Inorg. Chem., 2011, 2380.

73. L. Dostál, R. Jambor, A. Růžička and J. Holeček, Organometallics, 2008, 27, 2169.

74. I. Vránová, M. Alonso, R. Jambor, A. Růžička, J. Turek and L. Dostál, Chem. Eur. J., 2016, 23, 2340.

75. C. Ganesamoorthy, C. Wölper, L. Dostál and S. Schulz, J. Organomet. Chem., 2017, 845, 38.

76. I. Vránová, V. Kremláček, M. Erben, J. Turek, R. Jambor, A. Růžička, M. Alonso and L. Dostál, Dalton Trans., 2017, 46, 3556.

77. I. Vránová, M. Alonso, R. Jambor, A. Růžička, M. Erben and L. Dostál, Chem. Eur. J., 2016, 22, 7376.

78. M. Kořenková, V. Kremláček, M. Erben, R. Jambor, Z. Růžičková and L. Dostál, J. Organomet. Chem., 2017, 845, 49. 